\title{
Occurrence of Hepatitis C Virus infection in type 2 diabetic patients attending Plateau state specialist hospital Jos Nigeria James A Ndako*1, Georgebest O Echeonwu ${ }^{1}$, Nathaniel N Shidali², Iliyasu A Bichi ${ }^{1}$, Grace A Paul${ }^{1}$, Ema Onovoh ${ }^{1}$ and Lilian A Okeke ${ }^{1}$
}

Address: ${ }^{1}$ Department of Virology, Federal College of Veterinary and Medical Laboratory Technology, Vom, Nigeria and ${ }^{2}$ Department of Medical Laboratory Sciences, University of Maiduguri, Nigeria

Email: James A Ndako* - ndakoj@yahoo.co.uk; Georgebest O Echeonwu - gon612echeonwu@yahoo.com; Nathaniel N Shidali - shidalinn@yahoo.com; Iliyasu A Bichi - iliyasubichi@yahoo.com; Grace A Paul - graceabu@yahoo.com; Ema Onovoh - emamuyoyo@yahoo.com; Lilian A Okeke - liliananyanwu@yahoo.com

* Corresponding author

Published: 8 July 2009

Virology Journal 2009, 6:98 doi:10.1186/1743-422X-6-98

This article is available from: http://www.virologyj.com/content/6/1/98

(c) 2009 Ndako et al; licensee BioMed Central Ltd.

This is an Open Access article distributed under the terms of the Creative Commons Attribution License (http://creativecommons.org/licenses/by/2.0), which permits unrestricted use, distribution, and reproduction in any medium, provided the original work is properly cited.
Received: 25 April 2009

Accepted: 8 July 2009

\begin{abstract}
Background: Glucose intolerance is observed more in patients with HCV infection compared with control subjects with liver disease, Initial studies suggested that Hepatitis $C$ virus infection may be an additional risk factor for the development of diabetes mellitus. This study was therefore carried out to determine the correlation of $\mathrm{HCV}$ infection and diabetes.

Methods: Three hundred (300) confirmed type 2 diabetic patients were screened for hepatitis C virus antibodies at the Plateau state specialist hospital, Jos, using Grand diagnostic test strip. Questionnaire comprising of age, sex, family history on diabetes, duration of disease and marital status were issued to subjects.

Results: Overall result showed that the prevalence rate of $\mathrm{HCV}$ infection was 33(II\%). In response to diabetic status, females subjects had a higher prevalence of $178(59.3 \%)$ compared to males 122(40.7\%). Those aged 47-57 recorded the highest seroprevalence $10(30.3 \%)$ to the Hepatitis C Virus, while Patients without family history of diabetes showed a higher seroprevalence of $13(39.4 \%)$. Subjects who never had any blood transfusion recorded a prevalence rate of $6(I 8.2 \%)$. Marital status showed no significant difference $[(P=0.275 ; P .0 .05)]$. Considering duration of developing diabetes, patients within the range of $\mathrm{I}-10$ years diabetic status recorded the highest prevalence rate $25(75.8 \%)$ compared to other ranges considered.
\end{abstract}

Conclusion: This study hence, suggests a relatively strong association between HCV infection and diabetes, this therefore call for an urgent approach strategy in the control and management of this disease of the endocrine system.

\section{Background}

Various epidemiological studies have suggested that hepatitis $\mathrm{C}$ virus (HCV) infection is a risk factor for the devel- opment of diabetes mellitus (DM) type 2. The etiological factors were initially thought to be cirrhosis but further studies differentiating between HCV and hepatitis B virus 
(HBV) related infection have shown that patient with HCV infection have a higher prevalence of Diabetes mellitus type-2 [1].

\section{Pathogenesis}

Most persons who become infected with HCV viraemia persist, accompanied by variable degrees of hepatic inflammation and fibrosis. Earlier studies of chronic HCV infection suggests that only a small number of hepatocytes become infected, but more recent studies suggest that $50 \%$ or more harbor the virus[2]. HCV is most efficiently transmitted through transfusion of infected blood, transplantation of infected organs, and sharing injection drug equipment [3].

\section{Diagnosis}

The diagnosis of HCV infection can be made by detecting either anti-HCV or HCV RNAof anti-HCV is recommended for routine testing of asymptomatic persons and should include use of both enzyme immunoassay (EIA) and supplemental or confirmatory testing with an additional, more specific assay. Use of supplemental antibody testing (i.e., RIBA) for all positive anti-HCV results of EIA is preferred, particularly in settings where clinical services are not provided directly [4].

\section{Aim}

Type 2 diabetes is a debilitating disease condition especially in people above 30 years of age and this may evolve throughout their life-span. Hence, the co-infection of type 2 diabetes and HCV has been established to worsen these condition, with this scenario it has become very necessary for a screening exercise to determine the prevalence rate of $\mathrm{HCV}$ among diabetic patients so as to increase awareness of the populace and health practitioners on the dangers of the co-infectious state of this virus with diabetes.

\section{Materials and methods}

Our study was carried out according to the ethical standards for human experimentation. After explaining the aim of the study and the possible need for blood tests, written informed consent were obtained and ethical clearance granted.

\section{Subjects}

The subjects included in this research project were 300 known type 2 diabetic patients attending the hospital for check-ups.

\section{Study Location}

The study was carried out at the plateau state specialist hospital, Jos South local government area, Plateau state.

\section{Sample Collection}

$3 \mathrm{ml}$ of blood was collected from each patient by venepuncture using sterile syringes and needles into a sterile container with a screw cap. The blood was allowed to clot, and the sera samples were dispensed into a dry clean cryovial and stored at $-20^{\circ} \mathrm{C}$ prior use.

\section{Method of Assay}

The grand diagnostic rapid test kit was used to analyze the samples for HCV antibodies. This is a rapid chromatographic immunoassay for the qualitative detection of antibody to HCV in serum.

\section{Questionnaire}

Structured questionnaire were administered to the subjects, which covers clinical characteristics, demographic characteristics and social behaviors, which could be possible risk factors to acquiring HCV.

\section{Statistical Analysis}

General descriptive analysis was used to analyze the responses from the questionnaire and results were expressed as percentages. The chi square test was used to compare categorical data at $95 \%$ confidence interval, odds ratio and significance level were taken at $\mathrm{P} \geq 0.05$.

\section{Results}

Seroprevalence of HCV among type 2 diabetes patients was found to be $11 \%$ (33 out of 300 type 2 diabetes patients were positive for anti-HCV antibody).

The age group of 47-57 years had a prevalence rate of $3.3 \%$, followed by those aged 69 years and above with $3.0 \%$, while subjects aged $36-46$ years recorded $2.3 \%$, in contrast individuals aged $25-35$ years recorded $0 \%$. These data showed a significant difference within the age groups as $\mathrm{P}>0.05$ with a chi-square value of 34.803 . example (table 1).

The females had $6.3 \%$ of positivity within while the males recorded 4.7. Despite the fact that females had a higher prevalence rate, statistically $\mathrm{P}>0.05$, it is hence not a significant value, example (table 2 ).

Considering individuals with family history of diabetes, it was realized that that those without family history had a higher prevalence of $6.7 \%$ while those with family history recorded a prevalence of $4.3 \%$. Using the chi-square test it was found that Pearson chi square value is 46.829 with a significant $\mathrm{P}$ value of $(\mathrm{P}<0.05)$, example (table 3$)$.

Blood transfusion history was also compared in HCV status in the type 2 diabetes patients. Those that never had any blood transfusion showed a higher prevalence rate of $9.0 \%$ while those with an evidence of blood transfusion 
Table I: Age distribution of HCV in type 2 diabetic patients.

\begin{tabular}{lllll}
\hline Age group & & Negative & Positive & Total \\
\hline \multirow{2}{*}{ 25-35 } & Count & 51 & 0 & 5 I \\
& \% within hcv status & $19.1 \%$ & $0 \%$ & $17.0 \%$ \\
& \% Total & $17.0 \%$ & $0 \%$ & $17.0 \%$ \\
\multirow{3}{36-46}{} & Count & 95 & 7 & 102 \\
& \% within hcv status & $35.6 \%$ & $21.2 \%$ & $34.0 \%$ \\
& \% Total & $31.7 \%$ & $2.3 \%$ & $34.0 \%$ \\
$\mathbf{4 7 - 5 7}$ & Count & 73 & 10 & 83 \\
& \% within hcv status & $27.3 \%$ & $30.3 \%$ & $27.7 \%$ \\
& \% Total & $24.3 \%$ & $3.3 \%$ & $27.7 \%$ \\
$\mathbf{5 8 - 6 8}$ & Count & 38 & 7 & 45 \\
& \% within hcv status & $14.2 \%$ & $21.2 \%$ & $15.0 \%$ \\
& \% Total & $12.7 \%$ & $2.3 \%$ & $15.0 \%$ \\
$\mathbf{6 9}$ above & Count & 10 & 9 & 19 \\
& \% within hcv status & $3.7 \%$ & $27.3 \%$ & $6.3 \%$ \\
& \% Total & $3.3 \%$ & $3.0 \%$ & $6.3 \%$ \\
Total & Count & 267 & 33 & 300 \\
& \% within hcv status & $100.0 \%$ & $100.0 \%$ & $100.0 \%$ \\
& \% Total & $89.0 \%$ & $11.0 \%$ & $100.0 \%$ \\
& & & & \\
\hline
\end{tabular}

Pearson Chi-square value $=34.803 P$ value $=.000$ i.e. $P<0.05$

recorded 2.0\%, showing a chi-square value of 15.223 and $\mathrm{P}<0.05$, example (table 4 ).

When marital status comprising those divorced, married, and single individuals was closely compared among those with HCV status a prevalence of $0 \%, 10.0 \%$, and $0.3 \%$ were obtained respectively with no significant difference recorded, example (table 5).

Considering the duration of diabetes condition among subjects recruited, in this study, participants were grouped into: $1-10$ years, $11-15$ years, and 16 years above. Those with 1-10 years of Diabetic condition showed a higher prevalence of $8.3 \%$, followed by $11-15$ years with $2.7 \%$,

Table 2: Distribution of HCV pattern based on the sex of individual screened.

\begin{tabular}{lllll}
\hline Sex & & Negative & Positive & Total \\
\hline \multirow{2}{*}{ Female } & Count & 159 & 19 & 178 \\
& \% within hcv status & $59.6 \%$ & $57.6 \%$ & $59.3 \%$ \\
\multirow{4}{*}{ Male } & \% Total & $53.0 \%$ & $6.3 \%$ & $59.3 \%$ \\
& Count & 108 & 14 & 122 \\
& \% within hcv status & $40.4 \%$ & $42.4 \%$ & $40.7 \%$ \\
\multirow{5}{*}{ Total } & \% Total & $36.0 \%$ & $4.7 \%$ & $40.7 \%$ \\
& Count & 267 & 33 & 300 \\
& \% within hev status & $100.0 \%$ & $100.0 \%$ & $100.0 \%$ \\
& \% Total & $89.0 \%$ & $11.0 \%$ & $100.0 \%$
\end{tabular}

Pearson Chi-square value $=0.047$

$P$ value $=0.828$ i.e. $P>0.05$
Table 3: Association of HCV among subjects with family history of diabetes.

\begin{tabular}{lllll}
\hline FHOD & & Negative & Positive & Total \\
\hline \multirow{2}{*}{ No } & Count & 255 & 20 & 275 \\
& \% within hev status & $95.5 \%$ & $60.6 \%$ & $91.7 \%$ \\
& \% Total & $85.5 \%$ & $6.7 \%$ & $91.7 \%$ \\
Yes & Count & 12 & 13 & 25 \\
& \% within hev status & $4.5 \%$ & $39.4 \%$ & $8.3 \%$ \\
\multirow{4}{*}{ Total } & \% Total & $4.0 \%$ & $4.3 \%$ & $8.3 \%$ \\
& Count & 267 & 33 & 300 \\
& \% within hov status & $100.0 \%$ & $100.0 \%$ & $100.0 \%$ \\
& \% Total & $89.0 \%$ & $11.0 \%$ & $100.0 \%$ \\
\hline
\end{tabular}

FHOD = family history of diabetes.

Pearson Chi-square value $=46.829$

$P$ value $=.000$ i.e. $P<0.05$

while subjects 16 years above recorded $0 \%$, example (table 6).

\section{Discussion}

The prevalence rate of $11 \%$ recorded in this study is in agreement with the work of [5] who also recorded $11.5 \%$ against $2.5 \%$ when prevalence of HCV infection was checked among diabetic patients and blood donors respectively.

It was noted that patients who have been infected with HCV might have acquired diabetes due to damage to $\beta$ cells of the pancreas so as to induce diabetes. Where as those that have diabetes before being infected with HCV might suffer from insulin resistance resulting in more adverse effects of diabetes than those with HCV infection alone.

It was observed from this study that the occurrence of HCV among type 2 diabetes was higher in subjects aged 47-57 years with $3.3 \%$, This agrees with the findings of Mehta et. al. [1,6] who showed that individuals of $>40$ years are more prone to type 2 diabetes. Equaly in this study, subjects less than 36 years of age recorded a very low prevalence of HCV infection of $0 \%$, which also agrees with the report of Mehta et al. [1,7] that type 2 diabetes occurs more often with HCV infection in those older than 40 years of age. From the statistical analysis $P$ value is 0.000 which denotes $\mathrm{P}<0.05$ which is statistically significant.

The distribution of HCV infection in males and females were found to be $4.2 \%$ and $6.3 \%$ respectively, despite this fact, the statistical analysis gave a $\mathrm{P}$ value of 0.828 i.e. $\mathrm{P}<$ .05 which is not significant. Hence, it can be concluded that the distribution of HCV infection in both sexes is the same. 
Table 4: Association of HCV with blood transfusion amongst subjects screened.

\begin{tabular}{|c|c|c|c|c|}
\hline Blood transfusion & & Negative & Positive & Total \\
\hline \multirow[t]{3}{*}{ No } & Count & 259 & 27 & 286 \\
\hline & $\%$ within hcv status & $97.0 \%$ & $81.8 \%$ & $95.3 \%$ \\
\hline & $\%$ Total & $86.3 \%$ & $9.0 \%$ & $95.3 \%$ \\
\hline \multirow[t]{3}{*}{ Yes } & Count & 8 & 6 & 14 \\
\hline & $\%$ within hcv status & $3.0 \%$ & $18.2 \%$ & $4.7 \%$ \\
\hline & $\%$ Total & $2.7 \%$ & $2.0 \%$ & $4.7 \%$ \\
\hline \multirow[t]{3}{*}{ Total } & Count & 267 & 33 & 300 \\
\hline & $\%$ within hcv status & $100.0 \%$ & $100.0 \%$ & $100.0 \%$ \\
\hline & $\%$ Total & $89.0 \%$ & $11.0 \%$ & $100.0 \%$ \\
\hline
\end{tabular}

Pearson chi-square value $=15.223$

$P$ value $=.000$ i.e. $P<0.05$

When HCV status was analyzed against previous history of blood transfusion between those that have received and those that had never received blood transfusion, there was a significant difference with $\mathrm{P}$ value $=0.000$ in which those that consented to have had transfusion recorded a lower prevalence of $2.0 \%$ while those without prior history of blood transfusion recorded $2.7 \%$. This scenario suggests that infection with HCV in this group might not be as a result of blood transfusion. This finding agrees with the work of Simo et al. [5] were he did not observe any significant difference among subjects with previous blood transfusion to the HCV infection with $21.8 \%$ as against $16.7 \%$ in intravenous drug users, while $10.2 \%$ against $5.5 \%$ prevalence was observed between blood donors and diabetes patients with CV infection respectively.

A significant difference was observed in participants with a family history of diabetes mellitus and those without, with a $P$ value of 0.000 . Interestingly, this coincides with the work of Muller et al [8] and Del et al [9] Where it was found that increased occurrence was associated with fam-

Table 5: Association of Marital status with HCV in type 2 diabetes patients.

\begin{tabular}{lllll}
\hline Marital status & & Negative & Positive & Total \\
& & & & \\
\hline \multirow{2}{*}{ Divorce } & Count & 12 & 0 & 12 \\
& \% within hcv status & $4.5 \%$ & $.0 \%$ & $4.0 \%$ \\
& \% Total & $4.0 \%$ & $.0 \%$ & $4.0 \%$ \\
Married & Count & 235 & 32 & 267 \\
& \% within hcv status & $88.0 \%$ & $97.0 \%$ & $89.0 \%$ \\
& \% Total & $78.3 \%$ & $10.7 \%$ & $89.0 \%$ \\
Single & Count & 20 & 1 & 21 \\
& \% within hcv status & $7.5 \%$ & $3.0 \%$ & $7.0 \%$ \\
& \% Total & $6.7 \%$ & $.3 \%$ & $7.0 \%$ \\
Total & Count & 267 & 33 & 300 \\
& \% within hcv status & $100.0 \%$ & $100.0 \%$ & $100.0 \%$ \\
& \% Total & $89.0 \%$ & $11.0 \%$ & $100.0 \%$
\end{tabular}

Pearson Chi_square value $=2.582$

$P$ value $=0.275$ i.e. $P>0.05$ ily history of diabetes mellitus and this variable may be one of the reasons of higher frequency of diabetes mellitus type 2 in this group of patients. This study also shows that the prevalence of HCV infection in type 2 diabetes patients within the status had no significant difference with $P$ value $=0.275$ were $P>0.05$. This might suggest less risk of sexual transmission of HCV infection in this category of subjects.

In relation to the duration of type 2 diabetes onset, the analysis showed that those who suffered from diabetes within the period of 10 years had a seroprevalence of $8.3 \%$ as compared with those who had suffered from diabetes for 16 years and above with $0 \%$. This reflects the long term damage of the virus in the liver resulting to low sugar metabolism such organ due to hepatocyte damage. $[10,11]$.

\section{Conclusion}

There is a significant association between hepatitis $C$ virus and type 2 diabetes from the findings of this research work which might be on the increase, this calls for an

Table 6: Association of HCV with duration of type 2 diabetes amongst the patients screened.

\begin{tabular}{lllll}
\hline Years range & & Negative & Positive & Total \\
\hline \multirow{2}{*}{ I-10 } & Count & 256 & 25 & 281 \\
& \% within hev status & $95.9 \%$ & $75.8 \%$ & $93.7 \%$ \\
& \% Total & $85.4 \%$ & $8.3 \%$ & $93.7 \%$ \\
II-15 & Count & 8 & 8 & 16 \\
& \% within hev status & $3.0 \%$ & $24.2 \%$ & $5.3 \%$ \\
16 above & \% Total & $2.7 \%$ & $2.7 \%$ & $5.3 \%$ \\
& Count & 3 & 0 & 3 \\
& \% within hcv status & $1.1 \%$ & $.0 \%$ & $1.0 \%$ \\
Total & \% Total & $1.0 \%$ & $.0 \%$ & $1.0 \%$ \\
& Count & 267 & 33 & 300 \\
& \% within hcv status & $100.0 \%$ & $100.0 \%$ & $100.0 \%$ \\
& \% Total & $89.0 \%$ & $11.0 \%$ & $100.0 \%$ \\
\hline
\end{tabular}

Pearson chi-square value $=41.380$

$P$ value $=0.00$ i.e. $P<0.05$ 
urgent need to educate the populace on the dangers of the co-infection of HCV and diabetes it's also vital for all health care practioners to come to terms with the early diagnosis and Management of this condition in affected patients. However more prospective studies is recommended to include individuals at greater risk for both HCV infection and type 2 Diabetes to enable a firm relationship between these 2 conditions to be better established.

\section{Competing interests}

The authors declare that they have no competing interests.

\section{Authors' contributions}

JA conceived of the study and carried out the study design, and drafting of the manuscript. IB carried out the immunoassays, participated in data collection and Statistical analysis. GE Participated in drafting of the study design. NS Participated in study coordination. GP Participated in Data collection. EO Contributed in data analysis. LA Participated in the immunoassays. All authors read and approved the final manuscript.

\section{Acknowledgements}

I sincerely wish to thank my provost $\mathrm{Dr}$. Atanda O. Olabode for his interest in this study and providing the enabling space and facilities for this research. Deep appreciation also goes to $\mathrm{Dr}$ C.O.Chukwu of the Molecular Biology Laboratory of the college for his advice and intellectual support in this work.

\section{References}

I. Mehta SH, Brancati FL, Strathdee SA, Pankow JS, Netski D, Cores J: Hepatitis $C$ Virus infection and incident Type 2 diabetes. Hepatology. 2003, 38(I):50-56.

2. Agnello V, Abel G, Elfahal M, Knight GB, Zhang QX: Hepatitis C virus and other Flaviviridae viruses enter cells via low density lipoprotein receptor. Proc Natl Acad Sci U S A. 1999, 96(22):|2766-|277|.

3. Alter MJ: Epidemiology of Hepatitis C Virus. J Hepatology 1997 , 26:625-655.

4. Centers for Disease Control and Prevention: Recommendations for prevention and control of hepatitis $C$ virus (HVC) infection and HVC-related chronic disease. Morbidity and Mortality Weekly Report 1998, 47: I-39.

5. Simo R, Hernandez C, Geneca J, Jardi R, Mesa J: High Prevalence of Hepatitis C Virusin Diabetic Patients. Diabetes Care 1996, 19(9):998-1000.

6. Peterside AS: Liver Disease and Diabetes Mellitus. Diabetes Review 1994, 2:2-18.

7. Ozyilkan E, Arslan M: Increase Prevalence of Diabetes mellitus in patients with Hepatitis C Virus Infection. American Journal of Gastroenterology 1996, 91: | 480-1481.

8. Muller MJ, Pirlich M, Balks HJ, Selberg O: Glucose intolerance in liver cirrhosis: role of hepatic and non-hepatic influences. Eur J Clin Chem Clin Biochem 1994, 32(10):749-58.

9. Del Vecchio Blanco C, Gentile S, Marmo R, Carbone L, Coltorti M: Alterations of glucose metabolism in chronic liver disease. Diabetes Res Clin Pract 1990, 8:29-36.

10. Choo QL, Kuo G, Weiner AJ, Overby LR, Bradley DW, Houghton M: Isolation of a cDNA clone derived from a blood-borne nonA, non-B viral hepatitis genome. Science 1989, 244:359-362.

II. Mellor J, Holmes EC, Jarvis LM, Yap PL, Simmonds P: The International HCV Collaborative Study Group. Investigation of the pattern of hepatitis $C$ virus sequence diversity in different geographical regions: implications for virus classification. J Gen Virol 1995, 76:2493-2507.
Publish with Bio Med Central and every scientist can read your work free of charge

"BioMed Central will be the most significant development for disseminating the results of biomedical research in our lifetime. "

Sir Paul Nurse, Cancer Research UK

Your research papers will be:

- available free of charge to the entire biomedical community

- peer reviewed and published immediately upon acceptance

- cited in PubMed and archived on PubMed Central

- yours - you keep the copyright
BioMedcentral 